\title{
Research on the different kinds of speed sensorless induction machine flux observer control technology
}

\author{
Chen guoliang, Wang Jinyu, Sun libing and Josep M. Guerrero \\ Shanghai Solar Energy S\&T Co., Ltd, Shanghai 201108, China
}

Keywords: Induction motor, flux estimation, speed-sensorless.

Abstract. A compensated voltage model is proposed in this paper, which consists of a second order band pass filter and its compensator. Based on this compensated voltage model, a new flux estimator is constructed. To solve this multiple equilibrium states problem, a method to improve the flux estimator is proposed and the different kinds of induction motor flux observer control technology are studied. The traditional model reference adaptive speed estimation method is modified and using the band pass filter compensated voltage model proposed in this paper as the reference model. The precision of speed estimation is improved. On the basis of this modified model reference adaptive speed estimation method, a speed sensorless induction machine vector control strategy is proposed and then validated through simulation.

\section{Introduction}

In recent years, induction motor speed sensorless vector control algorithm has achieved rapid development. Many scholars have studied deeply and provided a lot of practical ways. Especially, the speed adaptive full order observer method had been attracted widespread attention, which included induction motor model, observer feedback gain and the rotor speed adaptive law ${ }^{[1 \sim 5]}$. Traditional speed adaptive law is based on the Lyapunov stability theory or Popov super stability theory ${ }^{[6 \sim 7]}$. In order to speed up the convergence rate estimation error, the method of pole assignment is used usually in order to design for observer feedback gain matrix. However, many research and practical work have shown that, even in the absence of parameter error and measurement noise conditions, adaptive full order observer of induction motor drive system will produce an unstable phenomenon. This paper will discuss the stable operation of induction motor speed sensorless vector control based on the improved voltage model flux estimate method. Through theoretical analysis, a new speed adaptive observer method is proposed.

\section{Induction motor speed estimate model}

\section{Stationary reference frame}

The stator and rotor flux vector equations as follows:

$$
\begin{aligned}
& \psi_{s}=L_{s} i_{s}+L_{m} i_{r} \\
& \psi_{r}=L_{m} i_{s}+L_{r} i_{r}
\end{aligned}
$$

The stator and rotor voltage vector equations as follows:

$$
\begin{gathered}
u_{s}=R_{s} i_{s}+\frac{d \psi_{s}}{d t} \\
0=R_{r} i_{r}+\frac{d \psi_{r}}{d t}-j \omega_{r} \psi_{r}
\end{gathered}
$$

The rotor angular frequency $\omega_{\mathrm{r}}$ is contained in the equation(4), the rotor angular frequency $\omega_{\mathrm{r}}$ equations as follows:

$$
\omega_{r}=\frac{-\frac{d \psi_{r \alpha}}{d t}-\frac{1}{T_{r}} \psi_{r \alpha}+\frac{L_{m}}{T_{r}} i_{s \alpha}}{\psi_{r \beta}}
$$


Which, $\psi_{r \alpha}=\frac{L_{r}}{L_{m}}\left(\psi_{s \alpha}-L_{s}^{\prime} i_{s \alpha}\right) \psi_{r \beta}=\frac{L_{r}}{L_{m}}\left(\psi_{s \beta}-L_{s}^{\prime} i_{s \beta}\right) \psi_{s \alpha}=\int\left(u_{s \alpha}-R_{s} i_{s \alpha}\right) d t \psi_{s \beta}=\int\left(u_{s \beta}-R_{s} i_{s \beta}\right) d t$

According to the equation(5), the expression of rotor speed $\omega_{\mathrm{r}}$ includes the rotor flux differential term which wills produce a large glitch in the numerical calculation process.

\section{Stator flux rotating $M T$ reference frame}

The voltage and current equation of stationary reference frame as follows:

$$
u_{s}-\left(R_{s}+\frac{L_{s} R_{r}}{L_{r}}\right) i_{s}-L_{s}^{\prime} \frac{d i_{s}}{d t}=-\frac{R_{r}}{L_{r}} \psi_{s}+j \omega_{r}\left(\psi_{s}-L_{s}^{\prime} i_{s}\right)
$$

With the coordinate transformation into Stator flux rotating $d q$ reference frame, the equation as follows:

$$
\begin{gathered}
{\left[u_{s}-\left(R_{s}+\frac{L_{s} R_{r}}{L_{r}}\right) i_{s}-L_{s}^{\prime} \frac{d i_{s}}{d t}\right] e^{-j \rho_{s}}=-\frac{R_{r}}{L_{r}}\left|\psi_{s}\right|+j \omega_{r}\left(\left|\psi_{s}\right|-L_{s}^{\prime} i_{s}^{M}\right)} \\
-\frac{R_{r}}{L_{r}} \psi_{s}+j \omega_{r}\left(\psi_{s}-L_{s}^{\prime} i_{s}\right)=-\frac{R_{r}}{L_{r}}\left(\psi_{s M}+j \psi_{s T}\right)+j \omega_{r}\left(\psi_{s M}+j \psi_{s T}-L_{s}^{\prime}\left(i_{s M}+j i_{s T}\right)\right)
\end{gathered}
$$

Because it is carried in the stator flux orientation, so

$$
\left\{\begin{array}{l}
\psi_{s M}=\left|\psi_{s}\right| \\
\psi_{s T}=0
\end{array}\right.
$$

Put the he formula (9) into formula(8), so

$$
\left\{\begin{array}{l}
u_{M}=-\frac{R_{r}}{L_{r}}\left|\psi_{s}\right|+\omega_{r} L_{s}^{\prime} i_{s T} \\
u_{T}=\omega_{r}\left(\left|\psi_{s}\right|-L_{s}^{\prime} i_{s M}\right)
\end{array}\right.
$$

\section{Induction motor flux observer}

\section{Current models flux observer}

The equations of current models flux observer as follows:

Convert into a block diagram:

$$
\left\{\begin{array}{l}
\frac{T_{r}}{L_{m}} \frac{d \psi_{r \alpha}}{d t}=i_{s \alpha}-\frac{1}{L_{m}} \psi_{r \alpha}-\omega_{r} \frac{T_{r}}{L_{m}} \psi_{r \beta} \\
\frac{T_{r}}{L_{m}} \frac{d \psi_{r \beta}}{d t}=i_{s \beta}-\frac{1}{L_{m}} \psi_{r \beta}+\omega_{r} \frac{T_{r}}{L_{m}} \psi_{r \alpha}
\end{array}\right.
$$

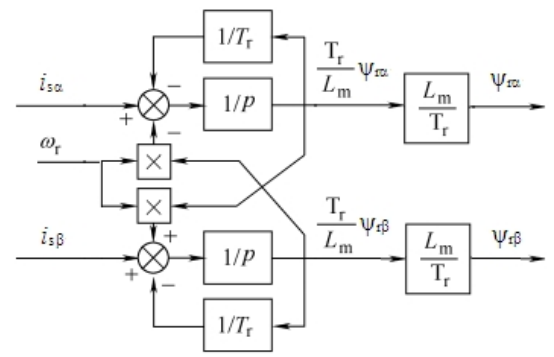

Fig. 1 the block diagram of current model flux observer

\section{Voltage models flux observer}

The equations of voltage models flux observer as follows:

$$
u_{s}=R_{s} i_{s}+\frac{d \psi_{s}}{d t}
$$

The flux observer formula as follows:

$$
\psi_{s}=\int\left(u_{s}-R_{s} i_{s}\right) d t
$$


The pure integral part will cause zero drift and the flux observer is not inaccurate. The method of eliminating zero drift is adopted by the first-order low-pass filter usually.

\section{Improved voltage model flux observer}

The improved voltage modle flux observer is given in this paper. The stator winding voltage, stator winding current through the filter $S /\left(S+\lambda_{H} \omega_{S} T_{S}\right)$ and the filter $1 /\left(S+\lambda_{L} \omega_{S} T_{S}\right)$ successively. Finally, the amplitude and phase compensation are executed. The block diagram of improved voltage model flux observer is shown in Fig.2. The simulation results of improved voltage model flux observer are shown in Fig.3. The observation value and actual values of rotor flux are shown in Fig.4 (a), Fig.4 (b) is the enlarged view of Fig.4 (a). It can be seen that the rotor flux observer effect is good and the deviation is relatively small.

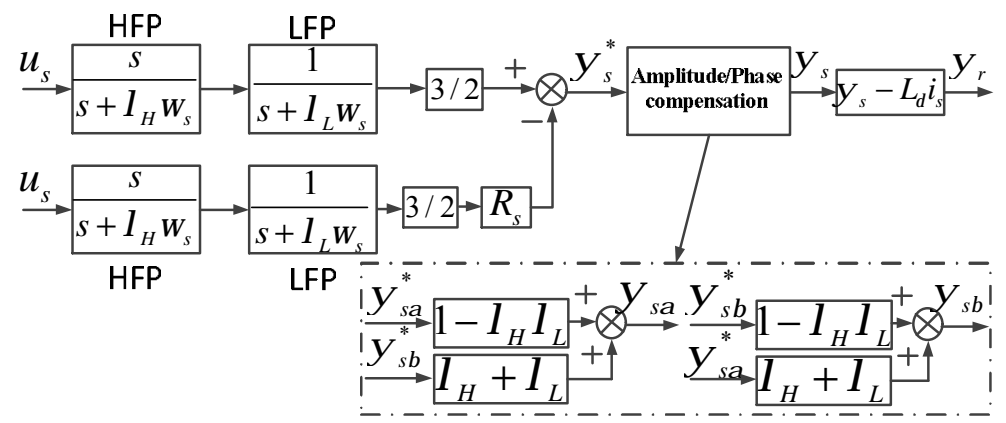

Fig. 2 the block diagram of improved voltage model flux observer

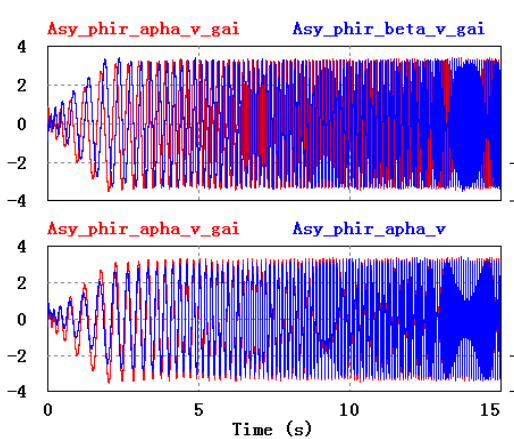

(a)

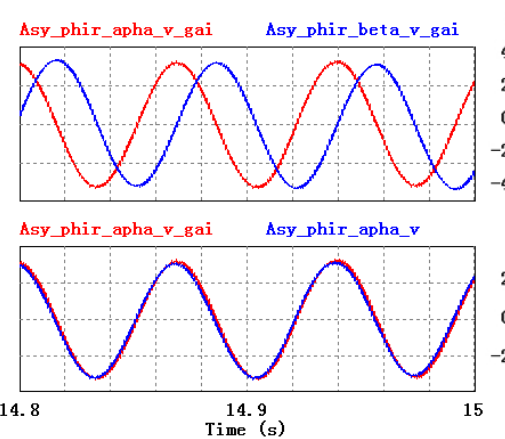

(b)

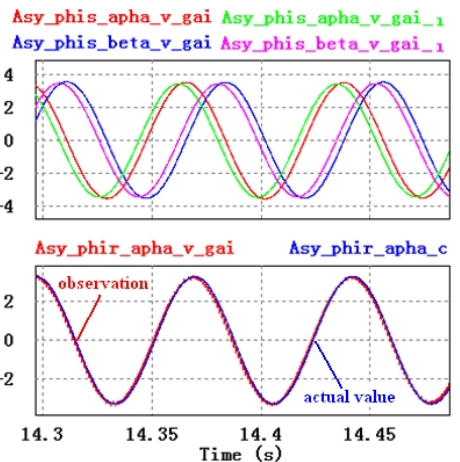

(c)

Fig. 3 the simulation results of improved voltage model flux observer

\section{Speed sensorless induction motor flux observer control technology}

The block diagram of model reference adaptive system is shown in the Fig. 4 which is a close loop system. The reference model usually monitored by the voltage model which observes the rotor flux, and the adjustable model usually monitored by the current model which observes rotor flux. The adaptive mechanism adopts flux cross-multiplication.

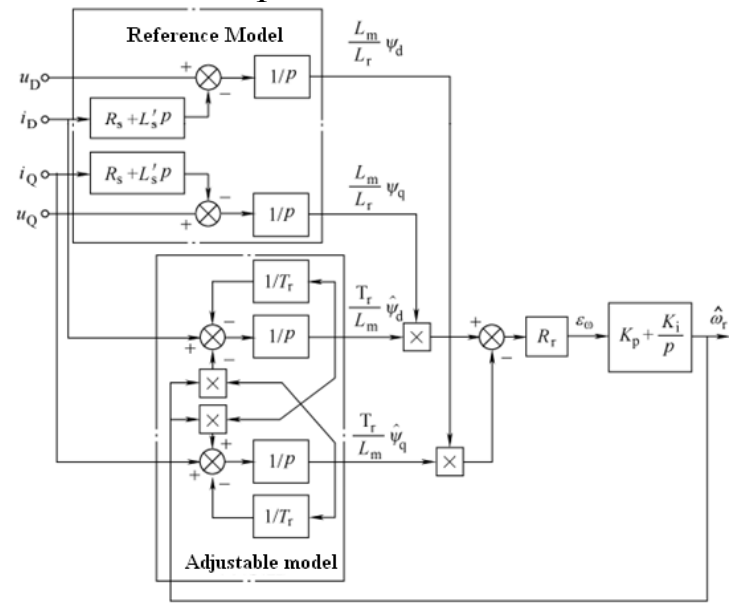

Fig. 4 the block diagram of model reference adaptive system 


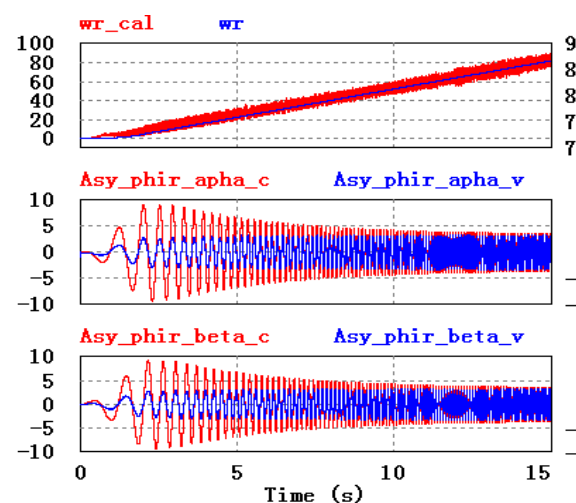

(a)

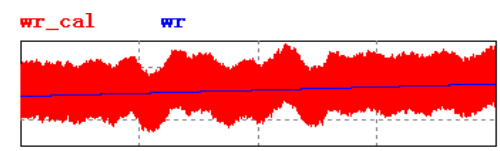

Asy_phir_apha_c Asy_phir_apha_v

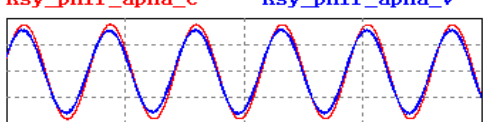

Asy_phir_beta_c Asy_phir_beta_v

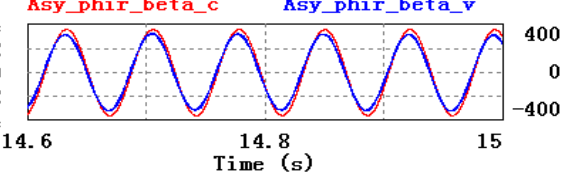

(b)

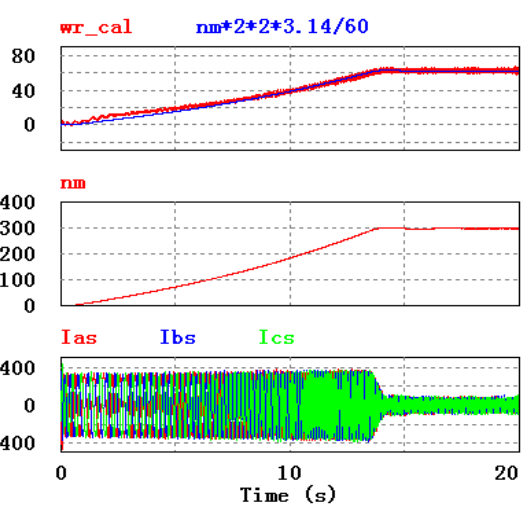

(c)

Fig. 5 the simulation results of improved voltage model flux observer

The observation value and actual values of rotor angular frequency $\omega_{\mathrm{r}}$, the current model and voltage flux observer of rotor winding flux are shown in Fig.5 (a), Fig.5 (b) is the enlarged view of Fig.5 (a). The observation value and actual values of rotor angular frequency $\omega_{\mathrm{r}}$ in the indirect field oriented closed loop control system are shown in Fig.5 (c). It can be seen that the speed observer effect is good and the deviation is relatively small.

\section{Summary}

This paper presents a novel model reference adaptive observer in the speed sensorless induction machine vector close loop control system, and the speed and flux observer effect is good.

\section{References}

[1] Kubota H , Matsuse K , Nakano T. DSP-based speed adaptive flux observer of induction motor[J] . IEEE Trans. on Industry Applications , 1993 , 29(2):344-348 .

[2] Yang G , Chin T H . Adaptive speed identification scheme for a vector controlled speed sensorless inverter induction motor drive [J] . IEEE Trans. on Industry Applications , 1993 , 29(4):820-825 .

[3] Wang Jian, Nian Xiaohong, Gui Weihua, et al . A new speed sensorless control method of asynchronous motor[J] . Proceedings of the CSEE , 2008 , 28(3):96-101(in Chinese)

[4] Tajima H , Guidi G , Umida H . Consideration about problems and solutions of speed estimation method and parameter tuning for speed sensorless vector control of induction motor drives[J]. IEEE Trans. on Industry Applications , 2002 , 38(2):1282-1289 .

[5] Suwankawin S, Sangwongwanich S. Design strategy of an adaptive full-order observer for speed-sensorless induction-motor drives tracking performance and stabilization [J]. IEEE Transactions on Industrial Electronics, 2006, 53(1): 96-119

[6] Marko Hinkkanen. Analysis and design of full-order flux observers for sensorless induction motors[J]. IEEE Transactions on Industrial Electronics, 2004, 51(5): 1033-2044.

[7] Hinkkanen M , Luomi J . Stabilization of regenerating mode operation in sensorless induction motor drives by full order flux observer design [J] . IEEE Trans. on Industry Electronics , 2004 , 51(6):1318-1328 . 
[8] Zhang Yongchang, Zhao Zhengming. Speed sensorless fuzzy vector control of induction motor using an adaptive observer[J]. Transactions of China Electro-technical Society, 2010, 25(3): 40-47.

the National international scientific and technological cooperation projects of China (2014DFG62610) 